\title{
Palm Kernel Oil Polyol-based Polyurethane as Shape Memory Material: Effect of Polyol Molar Ratio
}

\author{
Norshahli Mat Saad and Syazana Ahmad Zubir* \\ ${ }^{1}$ School of Materials and Minerals Resources Engineering, Universiti Sains Malaysia, \\ Engineering Campus, 14300 Nibong Tebal, Pulau Pinang. \\ ${ }^{*}$ Corresponding author: syazanazubir@usm.my
}

Published online: 25 December 2019

To cite this article: Mat Saad, N. \& Ahmad Zubir, S. (2019). Palm kernel oil polyolbased polyurethane as shape memory material: Effect of polyol molar ratio. J. Phys. Sci., 30(Supp. 2), 77-89, https://doi.org/10.21315/jps2019.30.s2.7

To link to this article: https://doi.org/10.21315/jps2019.30.s2.7

\begin{abstract}
Shape memory polyurethane (SMPU) has found application in a variety of field such as textile, sensors, structural and food industry due to its unique and composition dependent properties. However, most SMPU are synthesised using petroleum-based raw materials. This has triggered the effort in finding an alternative source of raw materials due to the environmental awareness. For this purpose, SMPU was synthesised based on palm kernel oil polyol (PKO-p) up to 40\% molar ratio in replace of petroleum-based polyol, polycaprolactone diol (PCL). SMPU was synthesised via two-step bulk polymerisation process incorporated with PKO-p, PCL as the switching segment, 4,4-methylene-bis (cyclohexyl isocyanate) and 1,4-butanediol. The SMPU were characterised by Fouriertransform infrared (FTIR) spectrometer, differential scanning calorimetry (DSC), tensile and shape memory test. The incorporation of PKO-p has enhanced the shape memory behaviour and tensile properties. The degree of soft segment crystallinity increased with the addition of PKO-p, hence improved its ability to fix the temporary shape upon cooling. Besides, the shape recovery remains $100 \%$ even at $40 \%$ of PKO-p suggesting the presence of sufficient amount of physical crosslinking to hold the permanent shape. On the other hand, SMPU at 10\% molar ratio of PKO-p showed high tensile strength and elongation at break.
\end{abstract}

Keywords: Microphase separation, palm kernel oil polyol, shape memory properties, polyurethane, SMPU 


\section{INTRODUCTION}

Shape memory polymers (SMPs) are an emerging class of polymers with the ability to memorise a macroscopic (permanent) shape and upon exposure to external stimulus. ${ }^{1}$ They have gained widespread attention in both industrial and academic fields due to lightweight, low cost, easy processing, high shape recovery strain, high shape recoverability, superior molding properties, potential biocompatibility and biodegradability. 2,3

Shape memory polyurethane (SMPU) falls under the SMP category which consists of alternating soft and hard segments that are linked along a macromolecular backbone and due to thermal incompatibility, hence they tend to display microphase separation structure. ${ }^{4}$ SMPUs are widely used and attracted much interest among the researchers due to its versatility as the properties may be tailored by changing its raw materials. ${ }^{5,6}$ Most SMPUs are petroleum based. However, due to the fluctuation of petroleum prices and depletion of fossil fuels resources as well as the awareness of the society towards the environmental concern has urged the replacement of petroleum-based polyols with natural oil-based polyol. ${ }^{7}$ Vegetable oils are the potential alternatives due to the abundance, relatively low cost and its renewability. ${ }^{8,9}$

Palm kernel oil (PKO) is obtained from the kernel part of the oil palm fruit and is considered palm oil waste. Due to its abundance in Malaysia, the researchers are encouraged to produce value-added products from PKO such as polyester in polyurethane (PU) industry. Hence, this study aims to produce SMPU with addition of palm kernel oil polyol (PKO-p) in replace of part of the petroleum-based polyol. PKO-p is chosen due to its low cost, biodegradable and environmental-friendly. To the best of our knowledge, there is no study reported on palm kernel oil polyol based SMPU so far. The molar ratio of PKO-p added was up to $40 \%$ in place of polycaprolactone diol (PCL). The thermal, tensile and shape memory properties of the produced SMPU were analysed and reported. The optimal molar ratio of PKO-p is essential towards an excellent performance of PU to be used as a shape memory material.

\section{EXPERIMENTAL}

\subsection{Materials}

PKO-p was supplied by Universiti Kebangsaan Malaysia, Malaysia with molecular weight of $435 \mathrm{~g} \mathrm{~mol}^{-1}$. PCL was obtained from Perstorp Polyols (Ohio, United States) with molecular weight of $4000 \mathrm{~g} \mathrm{~mol}^{-1}$ and hydroxyl value of $28 \mathrm{mg} \mathrm{KOH}$ 
$\mathrm{g}^{-1}$. 4,4-methylenebis (cyclohexyl diisocyanate) (HMDI), 1.4-butanediol (BD) and dibutyltin dilaurate (DBTDL) were supplied by Sigma-Aldrich (Petaling Jaya, Selangor, Malaysia).

\subsection{Synthesis of $\mathbf{P U}$}

PU was synthesised via two-step bulk polymerisation process in a $500 \mathrm{ml}$ three-neck round bottom flask held in a silicone oil bath and surrounded with $\mathrm{N}_{2}$ atmosphere. In the first step, HMDI and PCL were reacted for $2.5 \mathrm{~h}$ at $80^{\circ} \mathrm{C}$. Then, PKO-p was added and the mixing was prolonged for another $2 \mathrm{~h}$ with stirring speed of $190 \mathrm{rpm}$. In the second step, the prepolymer, BD and a few drops of DBTDL was added into Haake internal mixer and mixed for $15 \mathrm{~min}$ at $90^{\circ} \mathrm{C}$ with rotor speed of $50 \mathrm{rpm}$. The samples were then pressed using compression molding with thickness of $0.5 \mathrm{~mm}$ at $160^{\circ} \mathrm{C}$. The feed molar ratio of polyol/MDI/BD is shown in Table 1.

Table 1: Formulation of PU.

\begin{tabular}{lcc}
\hline Sample & Molar ratio (PCL/PKO-p/HMDI/BD) & Hard segment (\%) \\
\hline PUE-0 & $1 / 6 / 5$ & 32 \\
PUE-10 & $0.9 / 0.1 / 6 / 5$ & 34 \\
PUE-20 & $0.8 / 0.2 / 6 / 5$ & 36 \\
PUE-30 & $0.7 / 0.3 / 6 / 5$ & 39 \\
PUE-40 & $0.6 / 0.4 / 6 / 5$ & 42 \\
\hline
\end{tabular}

\subsection{Characterisation of PU}

The Fourier transform infrared (FTIR) spectroscopy (Spectrum One, Perkin Elmer, United States) spectra was recorded with a resolution of $4 \mathrm{~cm}^{-1}$ with wavelength of $550 \mathrm{~cm}^{-1}$ to $4000 \mathrm{~cm}^{-1}$.

Differential Scanning Calorimeter (Perkin Elmer) analysis was performed using two thermal scans. The first thermal scan starts from room temperature (RT) to $200^{\circ} \mathrm{C}$ at a heating rate of $10^{\circ} \mathrm{C} \mathrm{min}^{-1}$ followed by cooling to $-100^{\circ} \mathrm{C}$ at a rate of

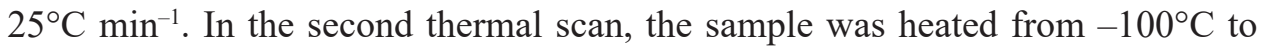
$250^{\circ} \mathrm{C}$ at a heating rate of $10^{\circ} \mathrm{C} \mathrm{min}^{-1}$.

X-ray diffraction (XRD) patterns were obtained using XRD diffractometer model Bruker AXS D8 Advance using $\mathrm{Cu}-\mathrm{K} \alpha \mathrm{X}$-ray source. The data was recorded using $2 \theta$ in the range of $10^{\circ}$ to $40^{\circ}$ and analysed using X'pert Highscore software. 
Bending test was performed to determine the shape memory effect. The sample was first heated at $60^{\circ} \mathrm{C}$ and bent into a ring-like shape by imposing a constraint. Then, the sample was soaked in the ice-water bath $\left(\sim 3^{\circ} \mathrm{C}\right)$ for 10 min without releasing the load. The constraint was then released and the retracted angle upon constraint removal $\left(\theta_{\text {cr }}\right)$ was recorded. The value of final angle $\left(\theta_{\mathrm{f}}\right)$ was recorded after the sample was reheated to $60^{\circ} \mathrm{C}$ and returned to its original shape. The percentage of shape fixity and shape recovery can be derived as follow:

$$
\begin{aligned}
& \text { Shape fixity }(\%)=\left(\theta_{\text {cr }} / 90^{\circ}\right) \times 100 \\
& \text { Shape recovery }(\%)=\left(\left[90^{\circ}-\theta_{\mathrm{f}}\right] / 90^{\circ}\right) \times 100
\end{aligned}
$$

Tensile test was performed using universal testing machine Instron 3366 machines based on ASTM D638. The testing was conducted using a load of $5 \mathrm{kN}$ with a speed of $50 \mathrm{~mm} \mathrm{~min}^{-1}$. Average reading of at least 7 samples was taken for analysis.

\section{RESULTS AND DISCUSSION}

\subsection{FTIR Analysis}

Figure 1 shows the FTIR spectrum of pristine SMPU and PKO-p based SMPU. The absence of NCO peak at $2260 \mathrm{~cm}^{-1}$ and the presence of NH peak in the range of $3331 \mathrm{~cm}^{-1}$ to $3347 \mathrm{~cm}^{-1}$ indicates the complete reaction in the formation of urethane linkages. ${ }^{10}$

The hydrogen bonding and phase separation was analysed using curve-fitting of FITYK software by deconvoluting the FTIR spectrum. The region of interest at $1634-1727 \mathrm{~cm}^{-1}$ which corresponds to carbonyl $(\mathrm{C}=\mathrm{O})$ group stretching band was analysed. The area under hydrogen bonded carbonyl $\left(\mathrm{A}_{\mathrm{HCO}}\right)$ and free carbonyl $\left(\mathrm{A}_{\mathrm{FCO}}\right)$ groups at $1664-1668 \mathrm{~cm}^{-1}$ (Band II and III) and $1726 \mathrm{~cm}^{-1}$ (Band IV) respectively was measured. The hydrogen bonding index (HBI), the degree of phase separation (DPS) and the degree of phase mixing (DPM) were calculated according to literature as in the following equation..$^{11,12}$

The carbonyl hydrogen bonding index (HBI):

$$
\mathrm{R}=\mathrm{C}_{\text {bonded }} \epsilon_{\text {bonded }} / \mathrm{C}_{\text {free }} \epsilon_{\text {free }}=\mathrm{A}_{\text {bonded }} / \mathrm{A}_{\text {free }}
$$

where $\mathrm{C}$ is the concentration; $\epsilon_{\mathrm{bonded}}$ and $\epsilon_{\text {free }}$ are the extinction coefficients of the bonded and free carbonyl groups, and the value of $\epsilon_{\text {bonded }} / \epsilon_{\text {free }}$ is fixed at 1 ; and $\mathrm{A}$ is the intensity of the characteristic absorbance. 
The degree of phase separation:

$$
\mathrm{DPS}=\mathrm{HBI} /(1+\mathrm{HBI})
$$

The degree of phase mixing (DPM):

$$
\mathrm{DPM}=1-\mathrm{DPS}
$$

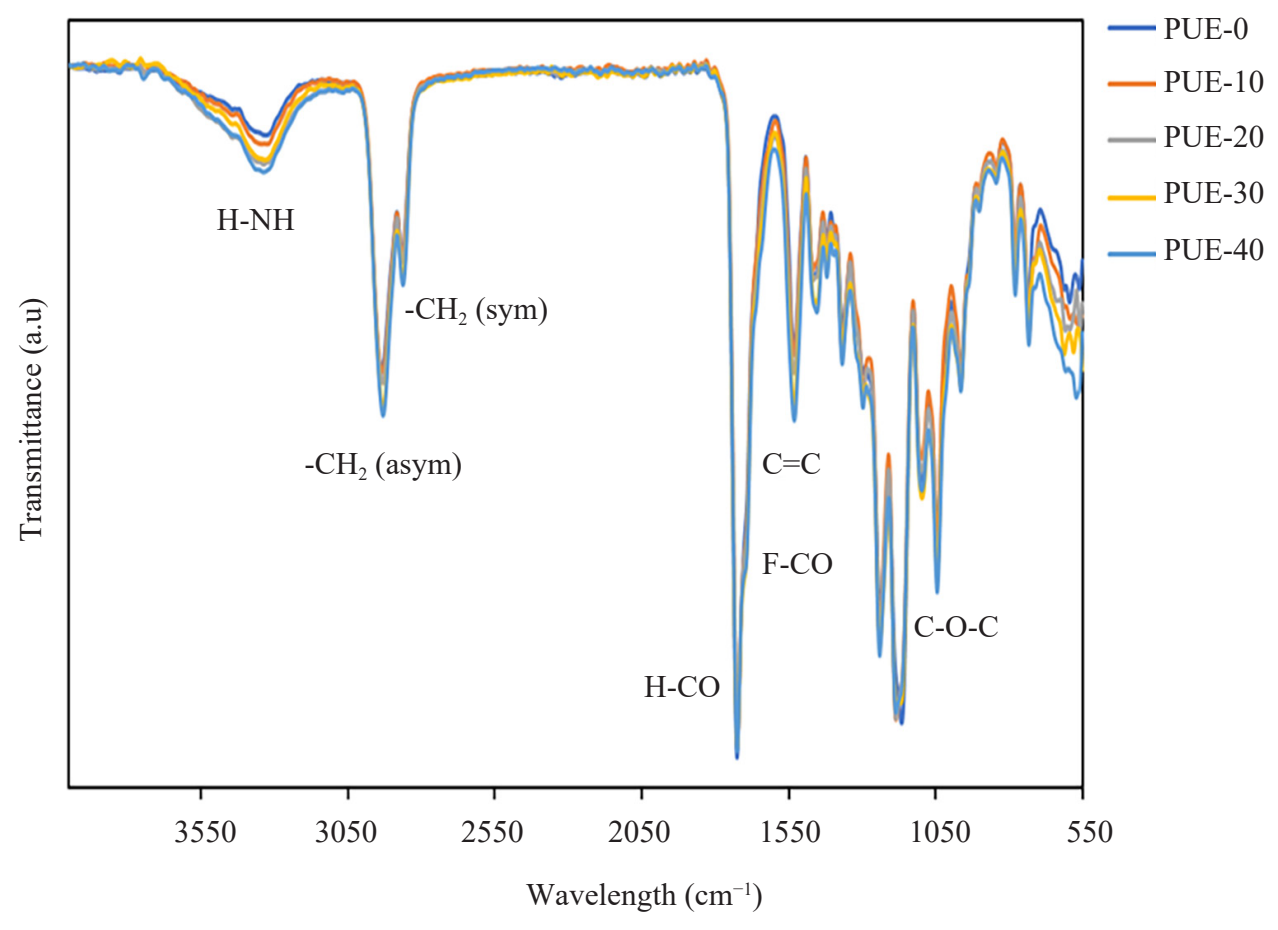

Figure 1: FTIR spectrum of PU.

Based on the results (Table 2), the value of HBI and DPS increased with increasing PKO-p content due to the increase of hard segment content which exhibit phase separation. In addition, the area ratio of $\mathrm{A}_{\mathrm{HCO}}$ at $1683-1698 \mathrm{~cm}^{-1}$ increased whereas the value of $\mathrm{A}_{\mathrm{FCO}}$ at 1723-1727 $\mathrm{cm}^{-1}$ decreased with increasing of PKO-p content. It is suggested that more hydrogen bonding was established as more PKO-p content was added in PU formulation. The interaction between $\mathrm{NH}$ urethane with $\mathrm{C}=\mathrm{O}$ groups of the urethane has increased the phase separation. 
Table 2: HBI, DPS and DPM of PU.

\begin{tabular}{lccccccc}
\hline Sample & Band I & Band II & Band III & Band IV & HBI & $\begin{array}{c}\text { DPS } \\
(\%)\end{array}$ & $\begin{array}{c}\text { DPM } \\
(\%)\end{array}$ \\
\cline { 2 - 5 } & F-CO $\left(\mathrm{cm}^{-1}\right)$ & H-CO $\left(\mathrm{cm}^{-1}\right)$ & H-CO $\left(\mathrm{cm}^{-1}\right)$ & H-CO $\left(\mathrm{cm}^{-1}\right)$ & & & \\
PUE-0 & 1725 & 1694 & 1665 & 1654 & & & \\
Area & 16.9 & 6.96 & 1.17 & 2.19 & 0.48 & 0.32 & 0.68 \\
PUE-10 & 1723 & 1693 & 1667 & 1634 & & & \\
Area & 15.89 & 6.23 & 3.07 & 0.99 & 0.58 & 0.37 & 0.63 \\
PUE-20 & 1724 & 1694 & 1666 & 1649 & & & \\
Area & 15.17 & 7.74 & 1.57 & 2.19 & 0.61 & 0.38 & 0.62 \\
PUE-30 & 1727 & 1698 & 1674 & 1646 & & & \\
Area & 14.36 & 8.18 & 3.59 & 1.54 & 0.82 & 0.45 & 0.55 \\
PUE-40 & 1726 & 1694 & 1664 & 1644 & & & \\
Area & 14.65 & 14.65 & 1.55 & 1.93 & 1.11 & 0.53 & 0.47 \\
\hline
\end{tabular}

\subsection{Crystallinity of $\mathrm{PU}$}

The analysis on the degree of crystallinity of PCL soft segments and hard segment is essential to determine the shape memory behaviour of the PU. Based on the XRD result (Figure 2), the presence of crystalline structure in the polyurethane system is shown by the existence of two diffraction peaks at $21.5^{\circ}$ and $23.8^{\circ}$ which belongs to crystalline PCL. The intensity of both peaks tends to increase with the amount of PKO-p represents better degree of chain orientation of the sample, hence suggesting that larger amount of crystalline soft segments was present with the addition of PKO-p content. It is interesting to note that the soft segment crystallinity increased with the addition of PKO-p. In this study, the addition of PKO-p has promoted the chain orientation during soft segment crystallisation process, hence increasing the degree of soft segment crystallinity in the PU system. ${ }^{13}$

\subsection{Surface Morphology}

Figure 3 shows the SEM micrograph of PU samples at different PKO-p content. The SEM images reveals that the surface is not smooth and some parts is inhomogeneous which may due to the presence of soft and hard segments. Sample PUE-30 and PUE-40 shows better mixing of the soft and hard segment domains. The difference in the observed SEM images may be attributed to the difference in the compositions of hard segment content as well as the presence of hydrogen bonding in their structure. ${ }^{14}$ Hard segment domains are indicated by the rough surface forming the compact region and disperse uniformly over the matrix of the soft segment domains. ${ }^{15}$ Thus, a rougher surface can be observed as the hard segment content is increased. 


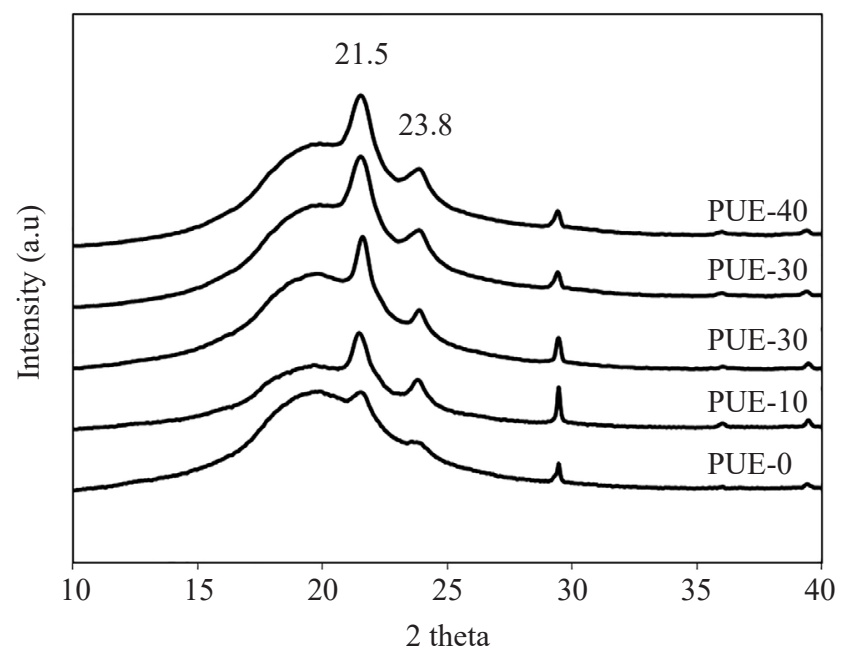

Figure 2: XRD diffractogram of PU.
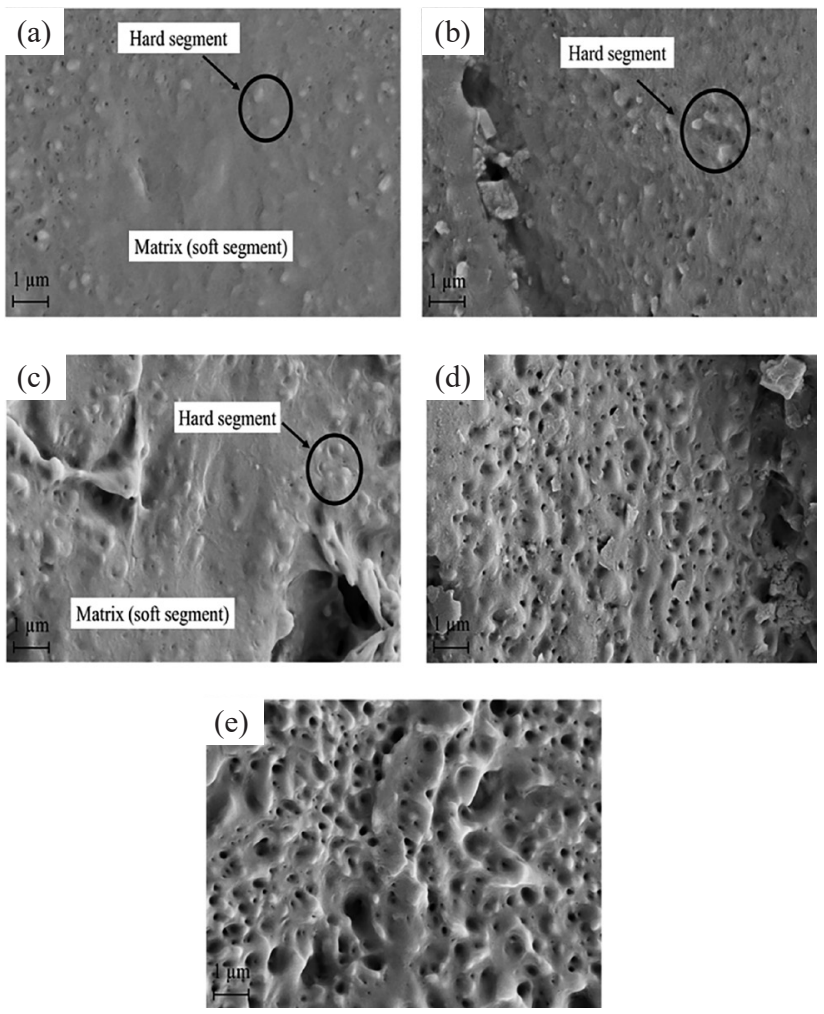

Figure 3: SEM micrographs of (a) PUE-0, (b) PUE-10, (c) PUE-20, (d) PUE-30, and (e) PUE-40. 


\subsection{Thermal Properties}

The thermal properties of PU were determined by DSC analysis. In view of the results obtained in Figure 4 and Table 3, the shifting of $\mathrm{T}_{\mathrm{g}}$ to a lower temperature can be explained by the structure of PKO-p. The slightly branched structure of PKO-p promotes the chain mobility thus increased the flexibility of the polymer structure. The $\mathrm{T}_{\mathrm{m}}$ peak became more intense with increasing of the PKO-p content indicating the increase of phase separation as more PKO-p is added (Figure 4). The percentage of crystallinity $\left(\mathrm{X}_{\mathrm{c}}\right)$ of PU increased with increasing PKO-p content. As the molar ratio of PKO-p increased, the amount of PCL decreased; however the value of soft segment crystallinity increased. It is suggested that the increment in the soft segment crystallinity may be due to the promotion of PCL crystallisation by the presence of PKO-p or due to participation of PKO-p in the formation of crystallised structure of PU. The trend obtained in this analysis is in agreement with the XRD result discussed previously.

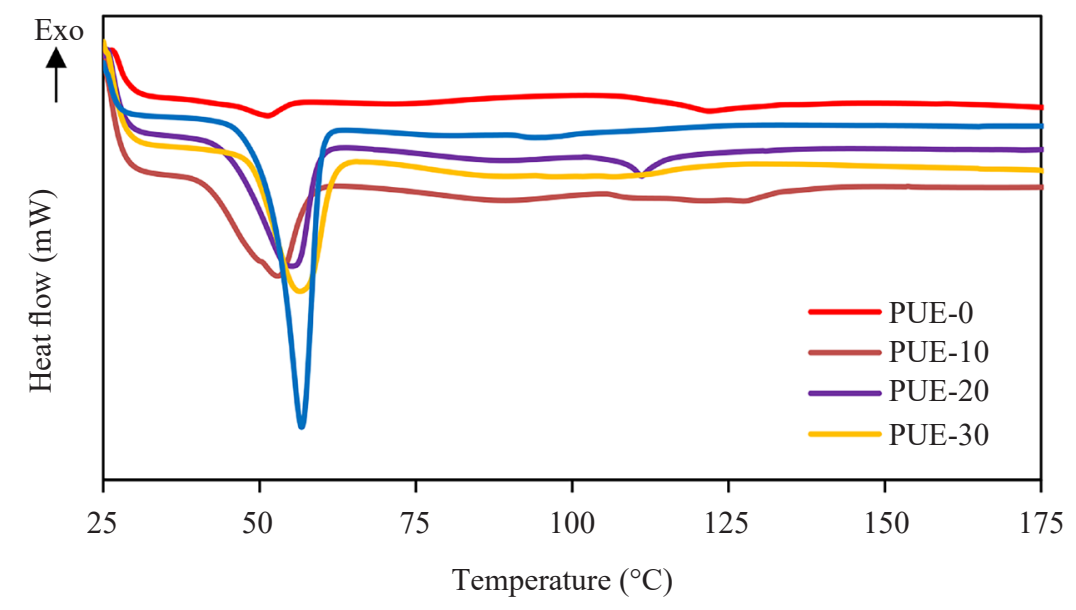

Figure 4: DSC thermogram of PKO-p based polyurethane.

Table 3: Thermal characteristic of PU.

\begin{tabular}{lccccc}
\hline \multirow{2}{*}{ Sample } & \multicolumn{3}{c}{ First heating scan } & & Second heating scan \\
\cline { 2 - 4 } & $\mathrm{T}_{\mathrm{m} 1}\left({ }^{\circ} \mathrm{C}\right)$ & $\Delta \mathrm{H}_{\mathrm{m} 1}\left(\mathrm{~J} \mathrm{~g}^{-1}\right)$ & $\mathrm{X}_{\mathrm{c}}(\%)$ & & $\mathrm{T}_{\mathrm{g}}\left({ }^{\circ} \mathrm{C}\right)$ \\
\hline PUE-0 & 51.3 & 1.8 & 1.3 & & -45.3 \\
PUE-10 & 52.9 & 14.1 & 10.1 & & -63.1 \\
PUE-20 & 55 & 17.2 & 12.3 & & -57.6 \\
PUE-30 & 56.3 & 15.3 & 11 & & -59.6 \\
PUE-40 & 56.7 & 26 & 18.7 & & -67.3 \\
\hline
\end{tabular}




\subsection{Tensile Properties}

It is observed that both stress at break and strain at break of PKO-p based PUE sample has similar trend as shown in Figures 5 and 6, respectively. PUE-10 showed a maximum tensile stress and strain at break after which it started to decrease as the PKO-p content increased up to $40 \%$. It is suggested that $10 \%$ molar ratio of PKO-p provides sufficient amount of hard segment domains to produce PU with good tensile properties. Hence, optimum hard segment content is achieved at $34 \%$. The increase of PKO-p has increased the hard segment content which hinder the mobility of polymer chain, thus lowering the value of strain at break. According to $\mathrm{Qu}$ et al., the uniformity size of the hard segment domains from the phase separated morphology exhibit higher tensile strength as it is difficult to disrupt the PU structure. ${ }^{16}$

Generally, the modulus increased with increasing PKO-p content (Figure 7). The increase in modulus value is due to the high hard segment content. The addition of PKO-p has formed more urethane linkages and hydrogen bonding formation between the hard segment domains, hence the hydrogen bonding index of the FTIR analysis has shown to be increased. On top of that, the presence of higher degree of soft segment crystallinity with increasing PKO-p content is the contributing factor to the increase of the modulus. Thus, as the PKO-p content is increased, the crystalline PCL coupled with the hard segment domains retard the chain mobility of PU polymer, hence increasing the modulus.

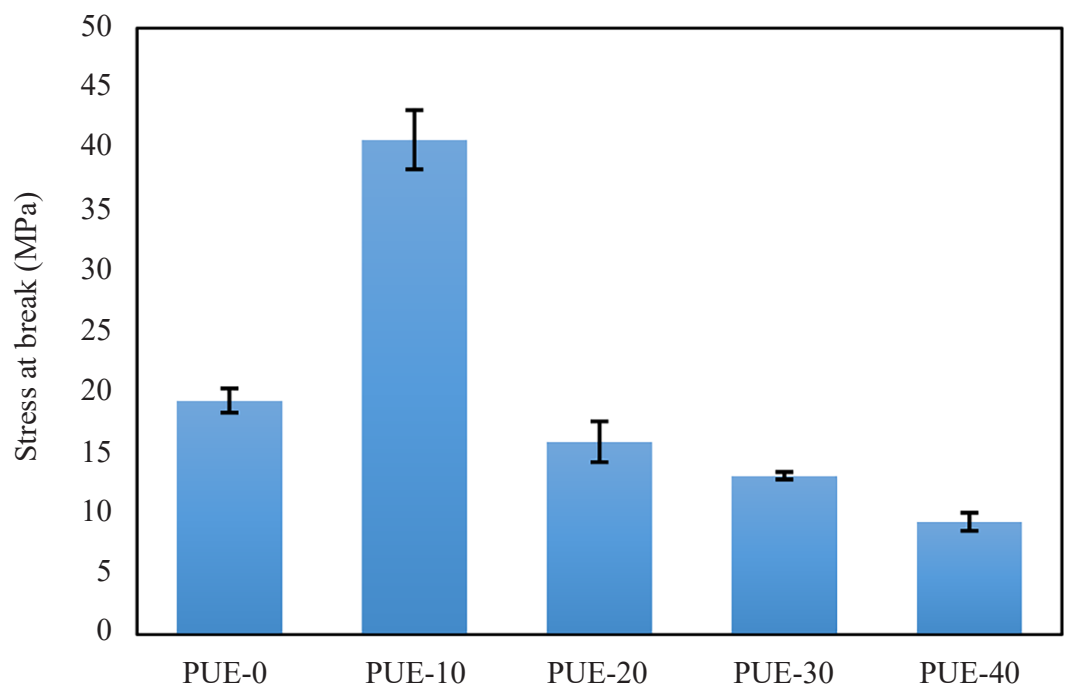

Figure 5: Stress at break of PU. 


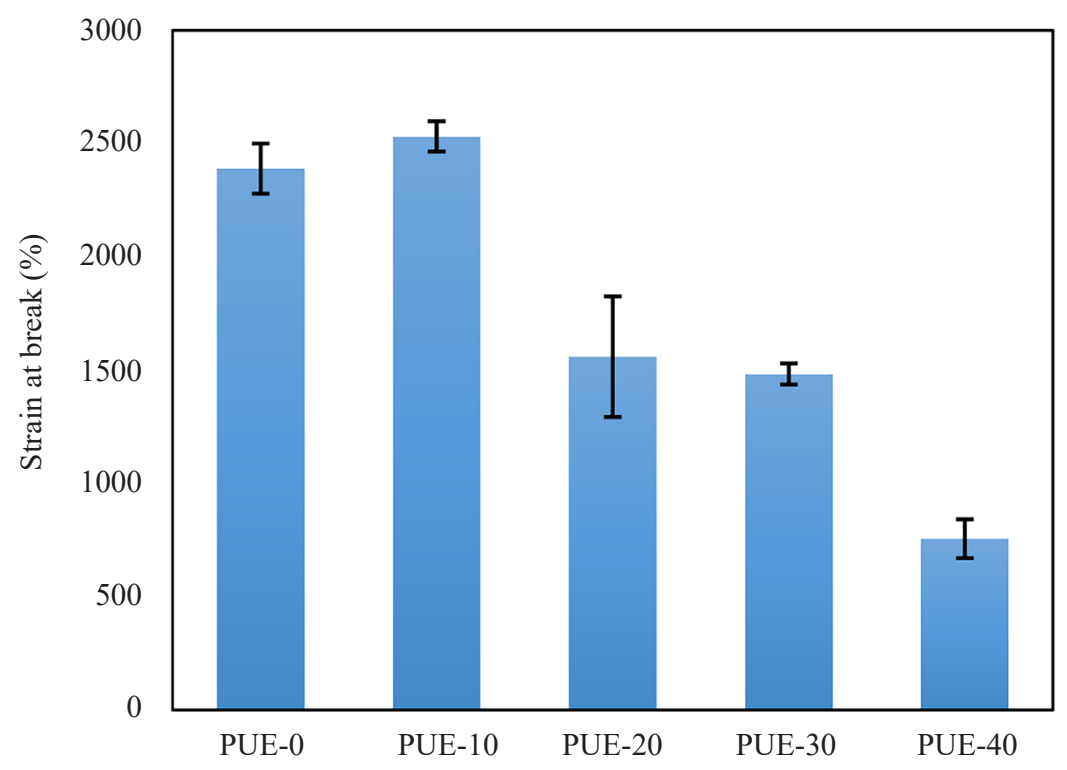

Figure 6: Strain at break of PU.

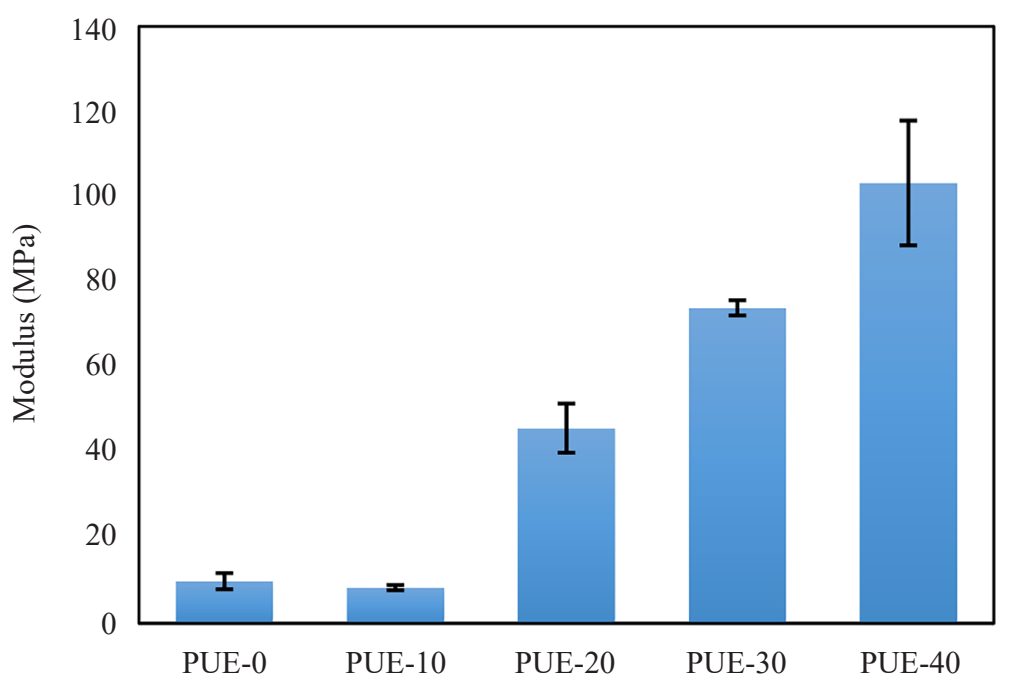

Figure 7: Modulus of PU.

\subsection{Shape Memory Properties}

The result of shape memory properties is presented in Table 5. The addition of PKO-p into PU has improved the shape memory behaviour. PUE-40 shows an excellent shape memory behaviour with $87 \%$ of shape fixity and $100 \%$ of shape 
recovery (Figure 8). The increase in the shape fixity is due to the increased formation of crystalline structure in PU, hence increasing the PU ability to fix the temporary shape. All samples show excellent shape recovery, reaching 100\% due to the greater degree of physical crosslinks present between hard segment domains at higher hard segment content.

Table 5: Shape memory properties.

\begin{tabular}{lcc}
\hline \multirow{2}{*}{ Sample } & \multicolumn{2}{c}{ Bending test } \\
\cline { 2 - 3 } & Shape fixity (\%) & Shape recovery (\%) \\
\hline PUE-0 & 53.3 & 100 \\
PUE-10 & 65.4 & 100 \\
PUE-20 & 73.6 & 100 \\
PUE-30 & 80.8 & 100 \\
PUE-40 & 87.2 & 100 \\
\hline
\end{tabular}

(a)

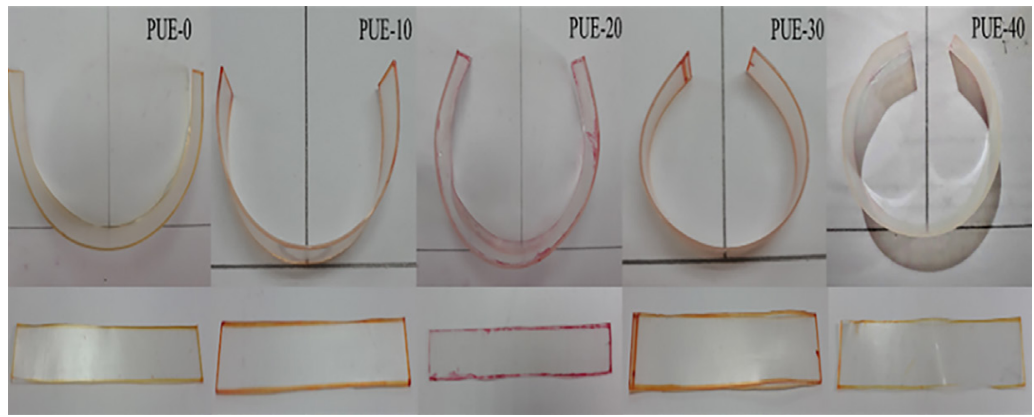

Figure 8: Shape memory properties of PU for (a) shape fixity, and (b) shape recovery.

\section{CONCLUSION}

A series of PKO-p based SMPU was successfully synthesised via two-step bulk polymerisation process. The addition of PKO-p in PU has increased the degree of crystallinity. The DPS has increased simultaneously with PKO-p content which contributed to the increase of crystallinity from $10.0 \%$ to $18.7 \%$ as the branched structure of PKO-p has induced the crystallisation of soft segment. Nevertheless, the amount of crystalline structures was sufficient for PU samples to exhibit good shape fixity which was up to $87.2 \%$ and achieved $100 \%$ shape recovery. Hence, the produced PKO-p based PU is suitable to be used as shape memory material. The structures and properties of this material can be further explored to suit a variety of engineering applications. 


\section{ACKNOWLEDGEMENTS}

The authors would like to express their utmost gratitude to the Ministry of Higher Education Malaysia under the Fundamental Research Grant Scheme (203/PBAHAN/6071324) for the financial support.

\section{REFERENCES}

1. Yang, B. et al. (2006). Effects of moisture on the thermomechanical properties of a polyurethane shape memory polymer. Polym., 47(4), 1348-1356, https://doi. org/10.1016/j.polymer.2005.12.051.

2. Hu, J. et al. (2012). Recent advances in shape-memory polymers: Structure, mechanism, functionality, modeling and applications. Progr. Polym. Sci., 37(12), 1720-1763, https://doi.org/10.1016/j.progpolymsci.2012.06.001.

3. Meng, Q. et al. (2007). Polycaprolactone-based shape memory segmented polyurethane fiber. J. Appl. Polym. Sci., 106(4), 2515-2523, https://doi. org/10.1002/app.26764.

4. Yilgör, I., Yilgör, E. \& Wilkes, G. L. (2015). Critical parameters in designing segmented polyurethanes and their effect on morphology and properties: A comprehensive review. Polym., 58, A1-A36, https://doi.org/10.1016/j. polymer.2014.12.014.

5. Zain, N. M. \& Zubir, S. A. (2016). Polyurethane-based smart polymers. In Hosseini, M. et al. (Eds.), Industrial applications for intelligent polymers and coatings. Cham: Springer, 293-312.

6. Sawpan, M. A. (2018). Polyurethanes from vegetable oils and applications: A review. J. Polym. Res., 25(8), 184, https://doi.org/10.1007/s10965-018-1578-3.

7. Zhang, C. et al. (2017). Recent advances in vegetable oil-based polymers and their composites. Progr. Polym. Sci., 71, 91-143, https://doi.org/10.1016/j. progpolymsci.2016.12.009.

8. Maisonneuve, L. et al. (2016). Vegetable oils: A source of polyols for polyurethane materials. Ocl., 23(5), D508-D35, https://doi.org/10.1051/ocl/2016031.

9. Pillai, P. K. et al. (2016). Metathesized palm oil and novel polyol derivatives: Structure, chemical composition and physical properties. Ind. Crops Prod., 84, 205-223, https://doi.org/10.1016/j.indcrop.2016.02.008.

10. Yücedag, F. et al. (2010). Antibacterial oil-based polyurethane films for wound dressing applications. J. Appl. Polym. Sci., 115(3), 1347-1357, https://doi. org/10.1002/app.30788.

11. Pavličević, J. et al. (2019). Structure-functional property relationship of aliphatic polyurethane-silica hybrid films. Progr. Org. Coat., 126, 62-74, https://doi. org/10.1016/j.porgcoat.2018.10.011.

12. Tien, Y. I. \& Wei, K. H. (2001). Hydrogen bonding and mechanical properties in segmented montmorillonite/polyurethane nanocomposites of different hard segment ratios. Polym., 42(7), 3213-3221, https://doi.org/10.1016/S00323861(00)00729-1. 
13. Ahmad Zubir, S. et al. (2018). Incorporation of palm oil polyol in shape memory polyurethane: Implication for development of cardiovascular stent. Polym. Adv. Technol., 29(12), 2926-2935, https://doi.org/10.1002/pat.4412.

14. Das, B. et al. (2013). Sunflower oil based biodegradable hyperbranched polyurethane as a thin film material. Ind. Crops Prod., 44, 396-404, https://doi. org/10.1016/j.indcrop.2012.11.028.

15. Oprea, S. (2010). Synthesis and properties of polyurethane elastomers with castor oil as crosslinker. J. Am. Oil Chem. Soc., 87(3), 313-320, https://doi.org/10.1007/ s11746-009-1501-5.

16. Qu, W. Q. et al. (2016). Synthesis and characterization of a new biodegradable polyurethanes with good mechanical properties. Chin. Chem. Lett., 27(1), 135138, https:// doi.org/10.1016/j.cclet.2015.07.018. 